\title{
HISTIOCYTIC GRANULOMATOSIS
}

\author{
Sir Walter Mercer and R. B. Duthie, Edinburgh, Scotland
}

The rarity of this somewhat obscure condition, and certain interesting features to be discussed in this case, seem to warrant its publication, even although it is a solitary case.

The title, suggested in 1941 by Farber, and modified subsequently by Weinmann and Sicher (1955) is favoured because the permanent and constant pathological feature is the presence of numerous histiocytes and granulomatous tissue. These cells, in the case under consideration, have undergone a transformation from the early stage where there were numerous eosinophil cells simulating an eosinophilic granuloma, to a later stage in which are seen numerous " foam cells" typical of a lipoid granulomatosis. This interesting change has been followed through a period of six years, and from this respect is unique.

Since Fraser's review (1935) much thought has been given to the disease with its varied expressions or manifestations and its terminology. Recent reviews by Jaffe and Lichtenstein (1944), Snapper (1949), Hill (1949), Fairbank (1951), and Lichtenstein (1953), describe the origin of the varying nomenclature, such as Hand-Schüller-Christian disease, or lipoid granulomatosis, the latter name being accredited to Greig by Fraser (1935), solitary granuloma of bone (Otani and Ehrlich 1940), non-lipoid histocytosis or Letterer-Siwe disease (Abt and Denenholz 1936), eosinophilic granuloma of bone (Mallory 1942, Jaffe and Lichtenstein 1944), non-specific granuloma of bone (Hill 1949), and, most recently, histocytosis X (Lichtenstein 1953). But a marked and important advance was made by Farber's observation in 1941 that " anatomically the underlying lesion in eosinophilic granuloma is related to the lesion of Schüller-Christian disease and that of Letterer-Siwe disease." This was further expounded by Green and Farber (1942) and in great detail by Jaffe and Lichtenstein, who described these three conditions as " different clinico-anatomic expressions of the same basic disorder." There has been much literature in America and in Europe, the main contribution from the latter being from Engelbreth-Holm et al. (1944), describing how eosinophilic granuloma, LettererSiwe disease and Schüller-Christian disease were all related phases of the same condition. A more recent and critical review of this nature was presented by Lichtenstein (1953), who has attempted to clarify and to integrate these clinical expressions under the heading of histiocytosis $\mathrm{X}$.

With this case, there is presented pathological evidence to support Green and Farber's original concept of the interrelationship between the conditions of eosinophilic granuloma and lipoid granulomatosis, as well as observations on pathogenesis and treatment of this condition.

\section{CASE REPORT}

In July 1949 a married woman aged thirty-one years was admitted to hospital complaining of pain in the left hip, thigh and knee regions. This was aching in quality and there had been a gradual loss of weight in the last six months.

On examination it was noted that there was a slight degree of exophthalmos present. There was local tenderness and there was limitation of all movements of the left hip.

Haematological investigations were normal except for the erythrocyte sedimentation rate, which was 50 millimetres in the first hour, and there was a hypochromic anaemia. There was no abnormality of the chemistry of the blood.

Radiographs showed " cystic" areas in the skull, pelvis, femora, scapulae and right humerus. Biopsy-A biopsy was carried out and the pathological report was: "The specimen consists of vascular granulation tissue which is heavily infiltrated with polymorphs, lymphocytes and histiocytes. A few giant cells of foreign-body type are seen. Many of the polymorphs are 


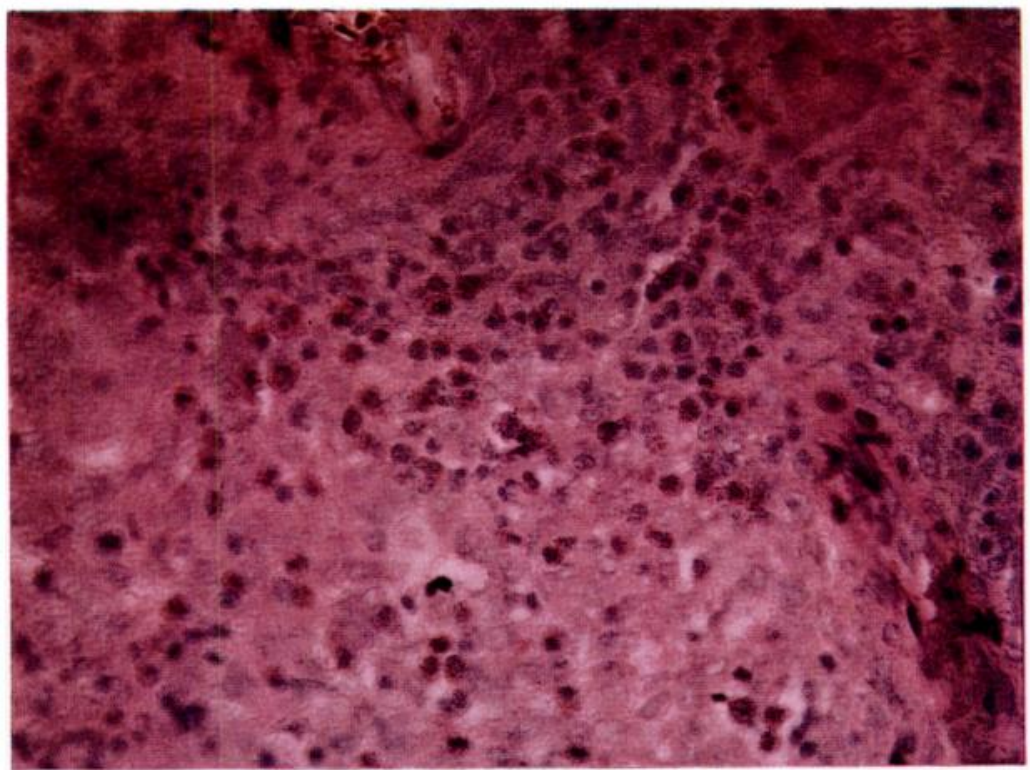

FIG. 1

Photomicrograph of section from the left ilium showing vascular granulation - tissue, heavily invaded by eosinophil polymorphs, lymphocytes and histiocytes. (Haematoxylin and eosin, $\times 400$.)

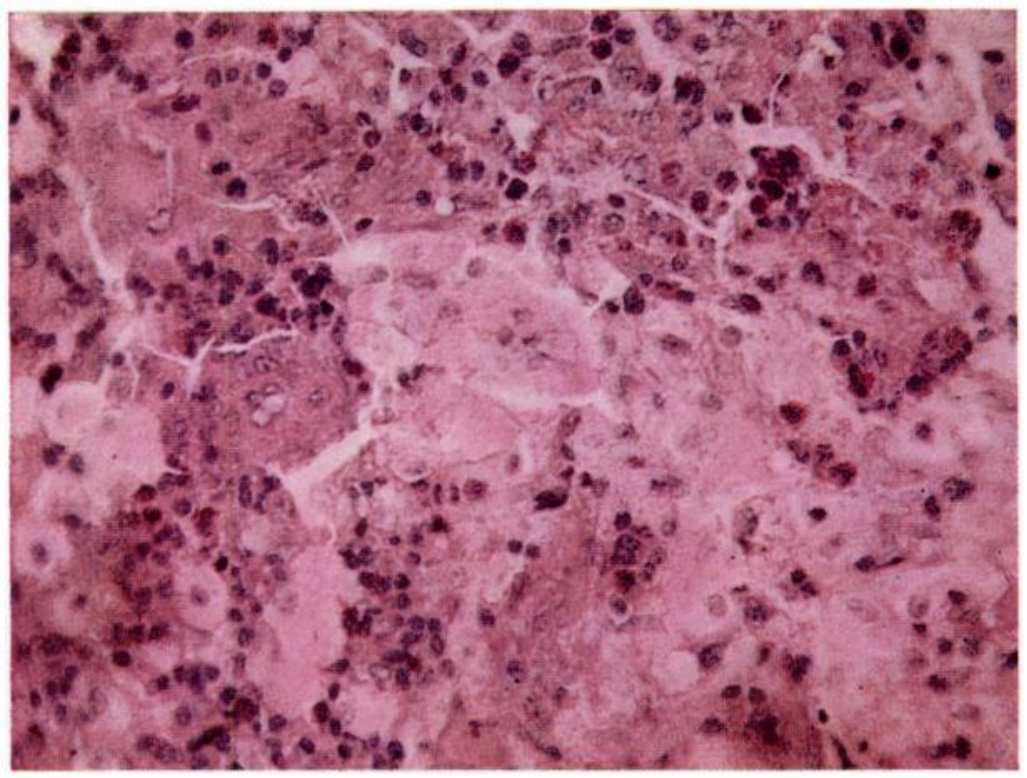

FIG. 2

Photomicrograph from same biopsy, showing area of necrosis with surrounding "foamy " cells and eosinophil polymorphs. (Haematoxylin and eosin, $\times 400$.) 
eosinophils (Fig. 1) which are widely distributed, and a large proportion of histiocytes which are 'foamy' cells (Fig. 2) are often conspicuously grouped. The 'foamy' cells and histiocytes (Fig. 3), however, dominate the picture and are often massed in sheets apart from the necrotic areas.

"The features are of a histiocytic granulomatous condition with eosinophilic and foamy characters - the latter feature would appear to be secondary, at least in part, to the necrosis. In conclusion, the condition is classified as a histiocytic granuloma."

Treatment-Deep x-ray therapy was given, with improvement in the symptoms of pain after an initial aggravation. The pain recurred however and continued throughout 1949 . The weight continued to fall.

In November 1950, on falling from a bus, she sustained a transverse fracture of the right femoral neck. A radiograph showed this to be through another area of diseased bone. She was immobilised in a plaster hip spica for six months without any radiological evidence

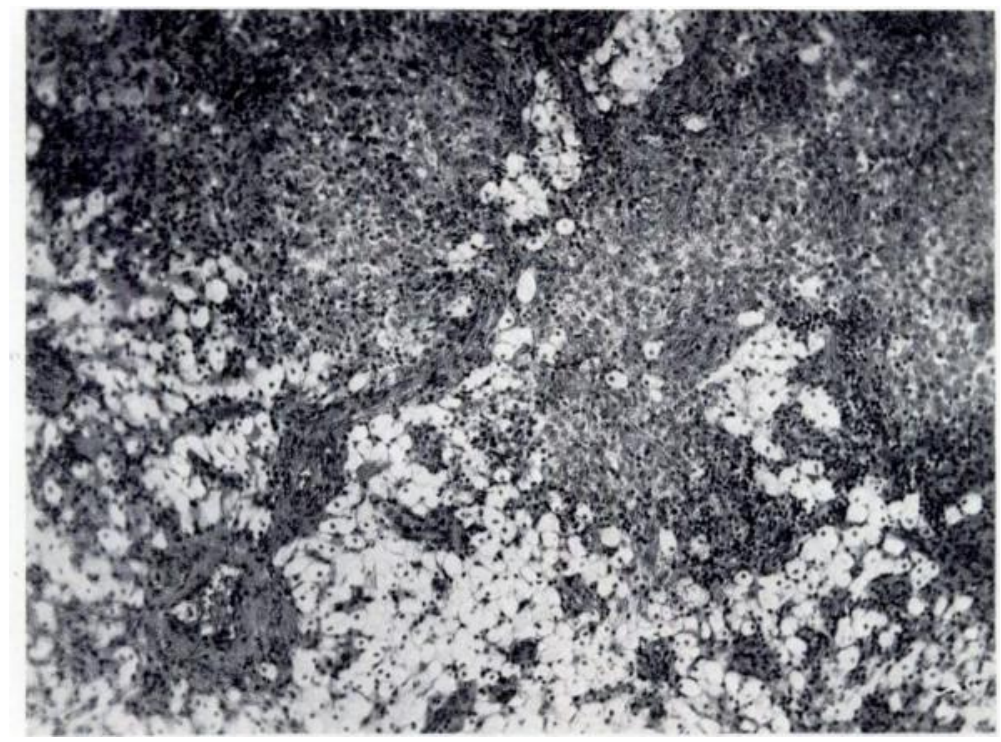

FiG. 3

Photomicrograph of same area showing sheets of histiocytes and " foamy" cells. $(\times 100$. $)$

of bone healing. In spite of this she was allowed up in a walking caliper and for six months she was ambulant.

In 1951 the pain became more acute in the right hip region, and she sustained a pathological fracture-intertrochanteric in type-in the left femur, with severe pain. On reaching for the nurse's arm shortly afterwards she experienced another episode of severe pain in the right upper arm, which proved to be the result of another pathological fracture-oblique in nature-through the midshaft area of the right humerus.

This patient was then placed into a plaster posterior shell with a right-angled arm support for the fractured humerus, and in this she was nursed both in hospital and at home during the next four years.

\section{Radiological examinations}

INVESTIGATIONS-1951-1955

Skull-There are translucent areas in the frontal, parietal and occipital regions (Fig. 4), varying in shape and size, but clear-cut and extending across suture lines. There is no surrounding osteosclerosis. The margins are irregular and appear to be "geographical " in 


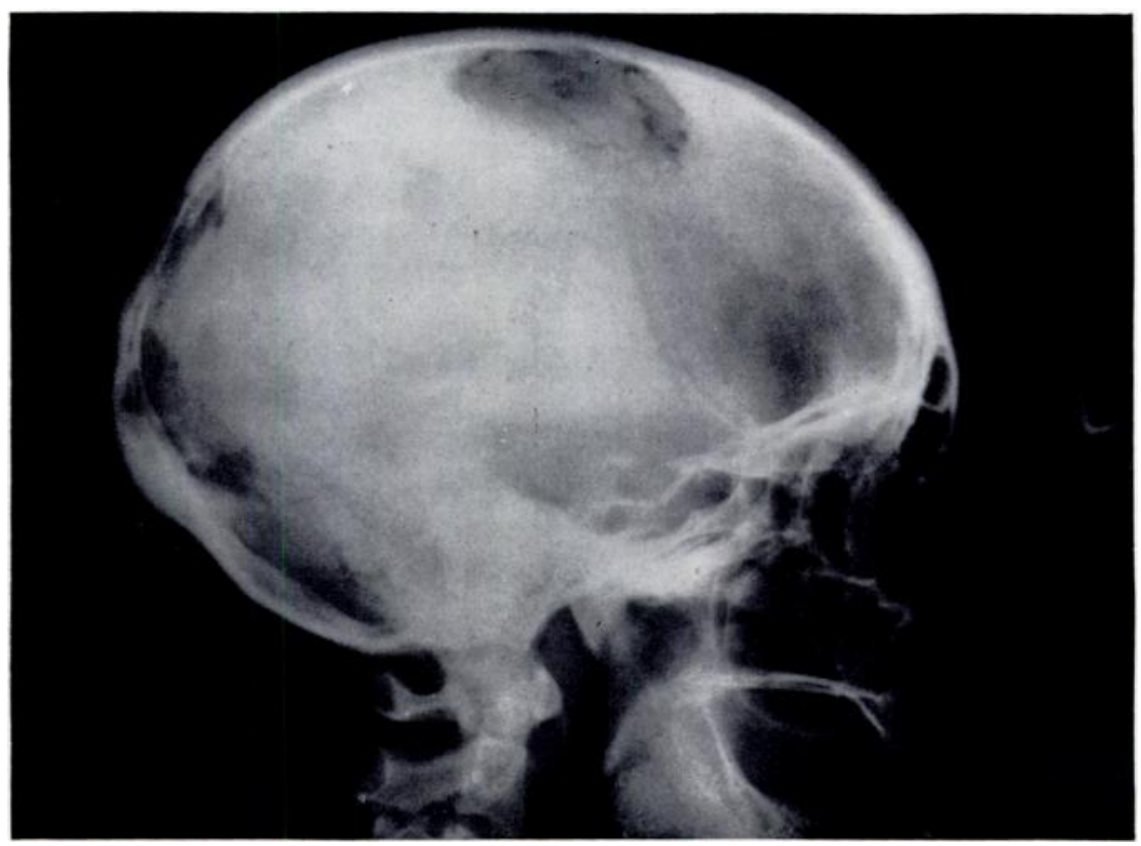

FIG. 4

Radiograph of the skull with translucent areas in the frontal, parietal and occipital regions.

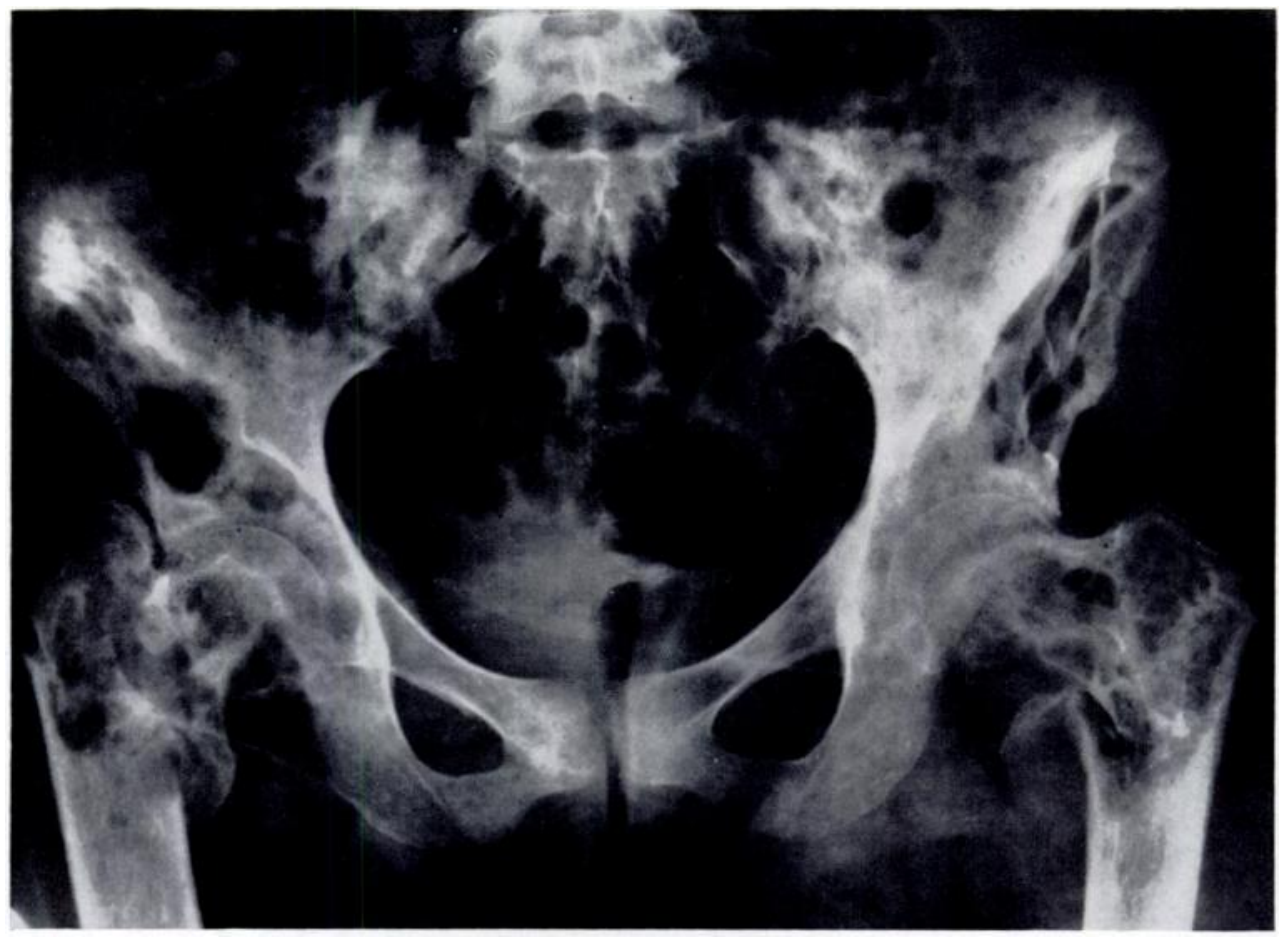

Fig. 5

Radiograph of the pelvis and upper femora showing the diseased areas, with the pathological fractures in the femora. 
outline. Neither the base of the skull nor the mandible is involved. These appearances have remained unchanged during these years.

Pelvis and upper femora-Numerous but typical translucent areas, without surrounding osteosclerosis, are seen in ilium, ischium and one small area in the pubis (Fig. 5). The cyst-like appearance is marked, particularly in the left ilium. The disease process is seen in both upper femora, with pathological fractures-transcervical and intertrochanteric on the right side, and transtrochanteric with avulsion of the lesser trochanter on the left side.

In Figure 6 there is seen the post-operative appearance of the hip regions with little attempt at regeneration of bone.

Shafts of femora-Pathological fractures are seen in the upper parts, through translucent, cyst-like areas. But in the shafts distal to these areas there is marked loss of thickness of cortex with an abnormal, striated appearance overlying the medullary cavity (Fig. 7).

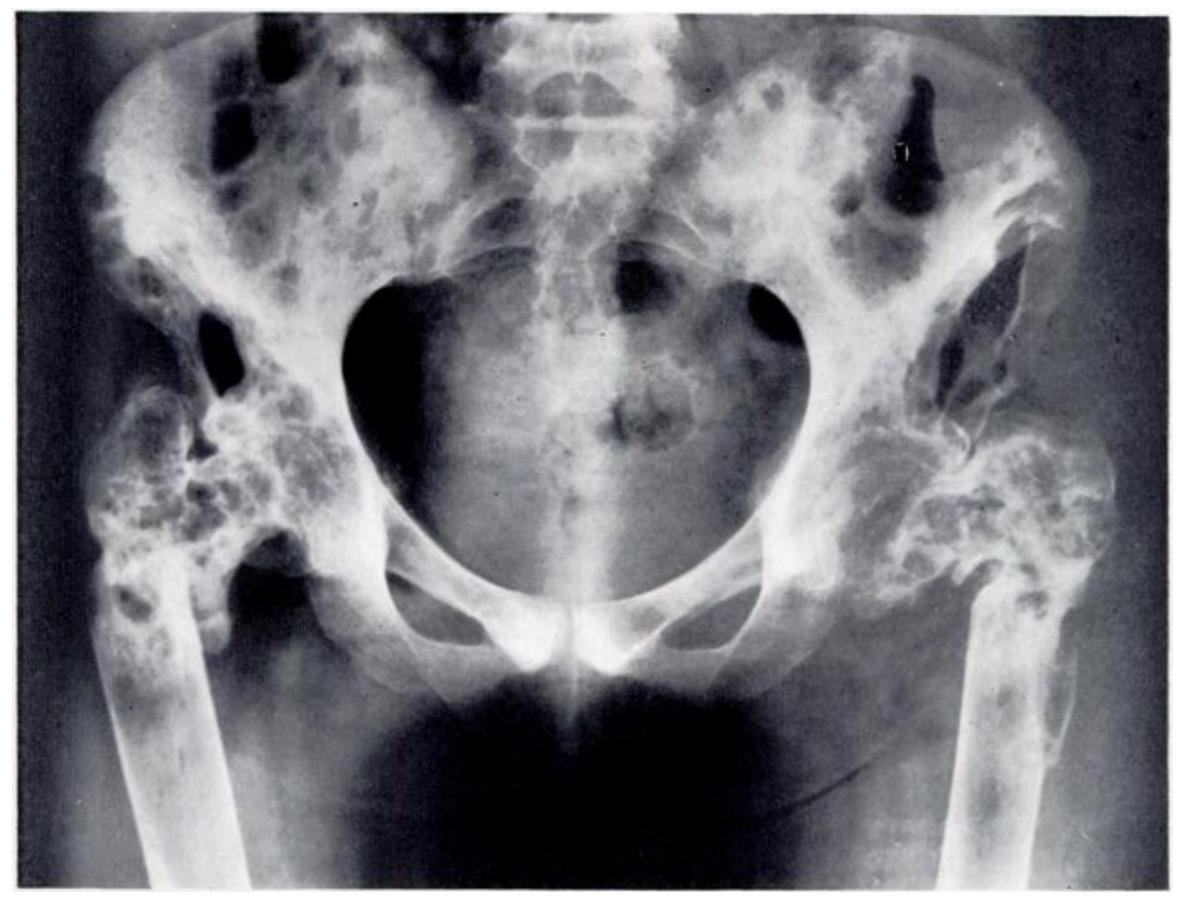

Fig. 6

Radiograph six months after operation showing little bone regeneration.

Shoulder girdles (Figs. 8 and 9)-The condition is seen in the acromion and coracoid processes as well as the neck and body of the scapulae. Both upper humeri are diseased and in one area there is destruction and "ballooning" outwards of the cortex on the medial side without any periosteal reaction.

Humerus-Each is involved in the upper half only. The pathological and spiral fracture through the midshaft of the right humerus is seen before (Fig. 10) and after immobilisation, and is incompletely united two years later (Fig. 11). The diseased area persists as a cyst-like space.

Chest-A generalised, diffuse infiltration or fine miliary change in the lung pattern of both lung fields is noted (Fig. 12).

Pathological examinations-Biopsy material from the greater trochanter of the left femur was obtained by open operation in December 1951. "The specimen is of soft consistence and is composed in the main of a tissue made up of accumulation of vacuolated histiocytes

VOL. 38 B, NO. 1, FEBRUARY 1956 
supported by fibroblastic granulation tissue which, in some areas, dominate the picture (Fig. 13). The histiocytes present a foamy appearance (Fig. 14), as a consequence of lipoid vacuolation. In regions where the granulation architecture predominates, leucocytic infiltration is often heavy, but the leucocytes exhibit degenerative changes and only a few can be recognised as eosinophil polymorphs or other specific varieties of cells. Irregularly scattered through the granulomatous background there are multinucleated giant cells.

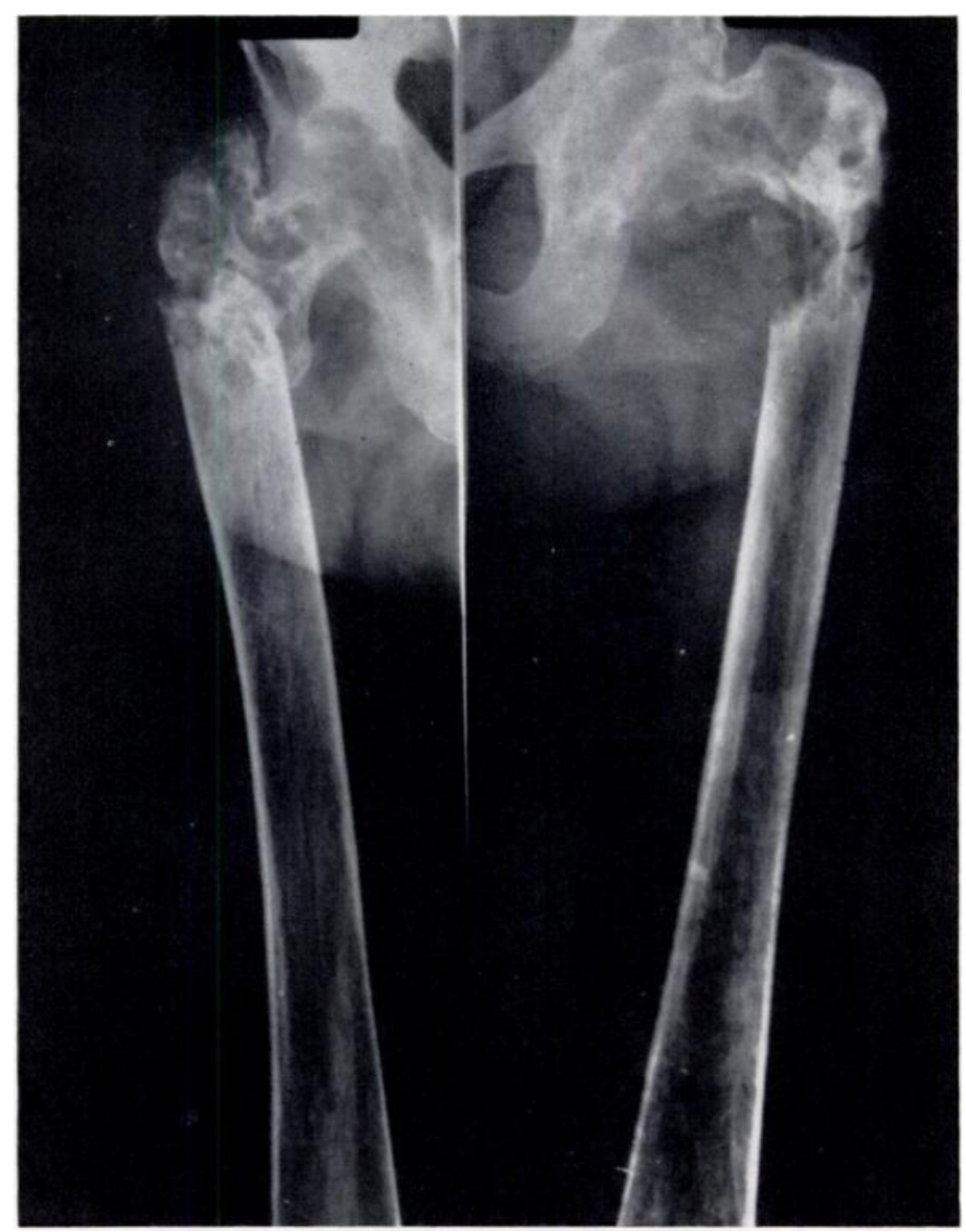

Fig. 7

Radiographs of the upper femora to show the pathological fractures and the striated appearance down the shaft of each bone.

" In conclusion, the tissue from the femur is showing the lipoid storage phase of a lipoidosis, namely Hand-Schüller-Christian's disease."

Biopsy material from the greater trochanter of the left femur was obtained by open operation in February 1952.

- The tissue is largely composed of close-packed histiocytes with finely vacuolated cytoplasm. These cells are arranged in clusters supported by a delicate framework composed of fibroblasts and narrow capillaries (Fig. 15) but in all fields the histiocytic component of the tissue predominates. There is both focal and diffuse infiltration by small round cells only a few of 


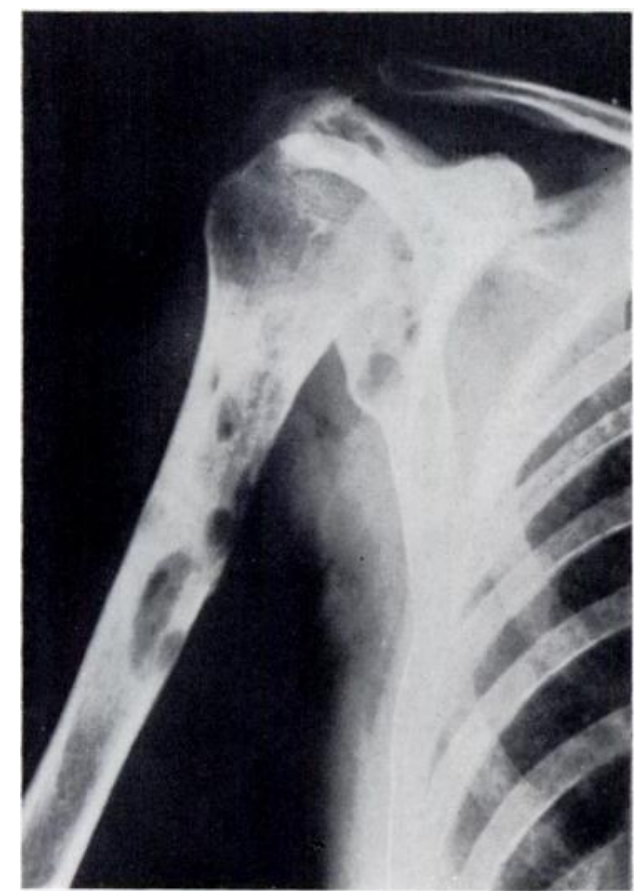

FIG. 8

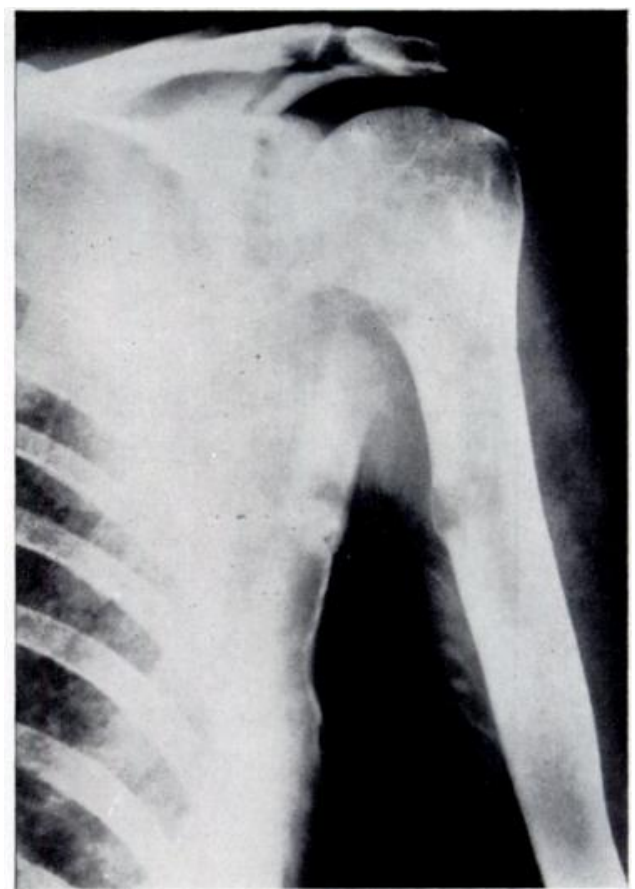

Fig. 9

There is seen involvement of the scapulae as well as both upper humeri. On the medial side of the left humerus (Fig. 9) there is a cyst-like space with "ballooning outwards" and destruction of the cortex.

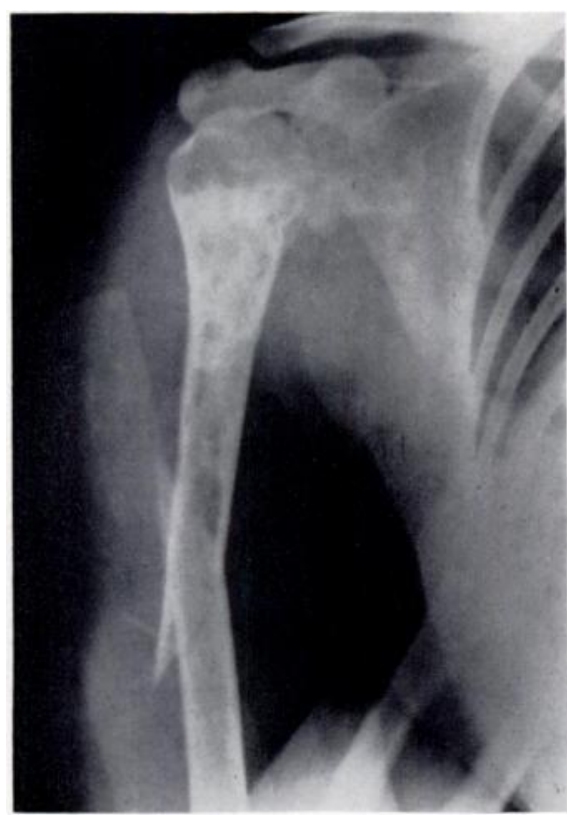

Fig. 10

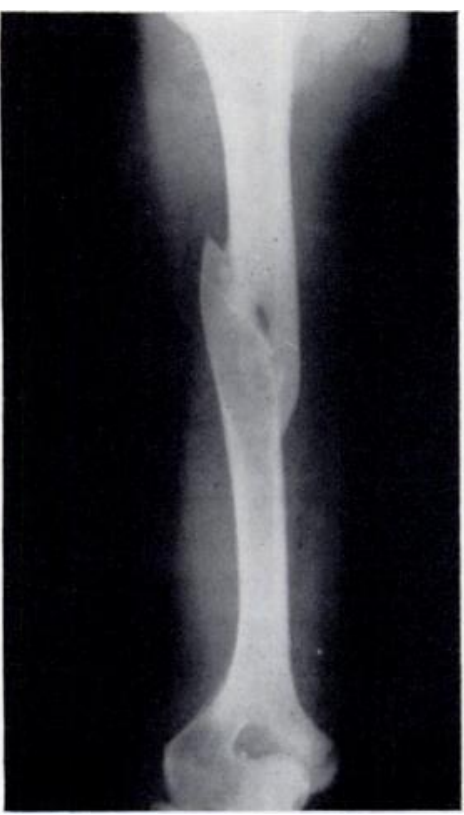

Fig. 11

Shows the pathological fracture through the midshaft area of the right humerus and the amount of repair after two years. 


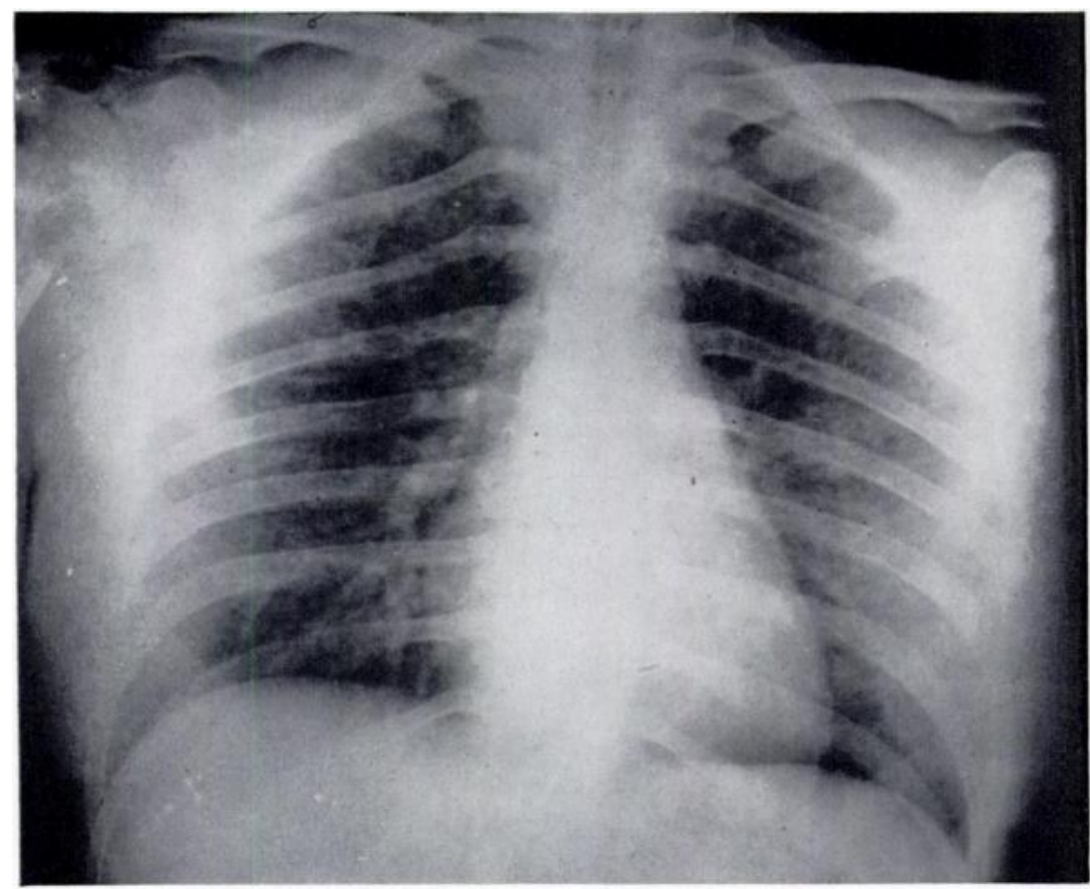

FIG. 12

Radiograph of the chest showing generalised and diffuse infiltration of both lung fields.

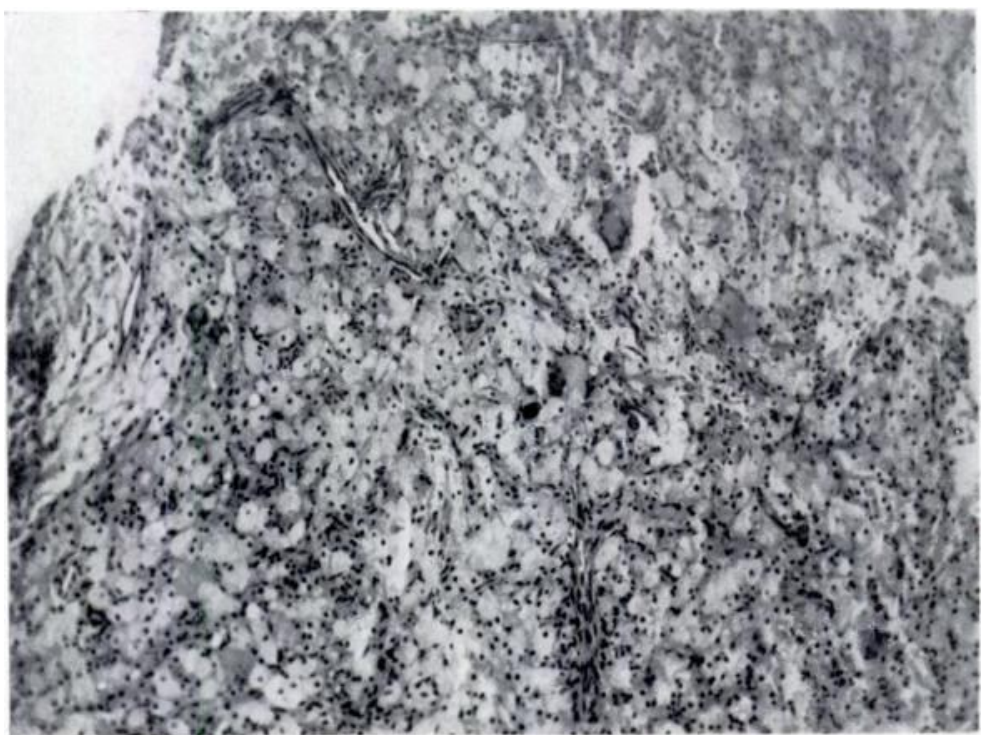

Fig. 13

Photomicrograph of a section from the left greater trochanter containing numerous vacuolated histiocytes, with some fibroblastic granulation tissue.

$$
(100 .)
$$


which are recognisable and a scattering of giant cells. No significant difference can be detected between the tissue comprising the present biopsy and that of the previous biopsy from the same subject."

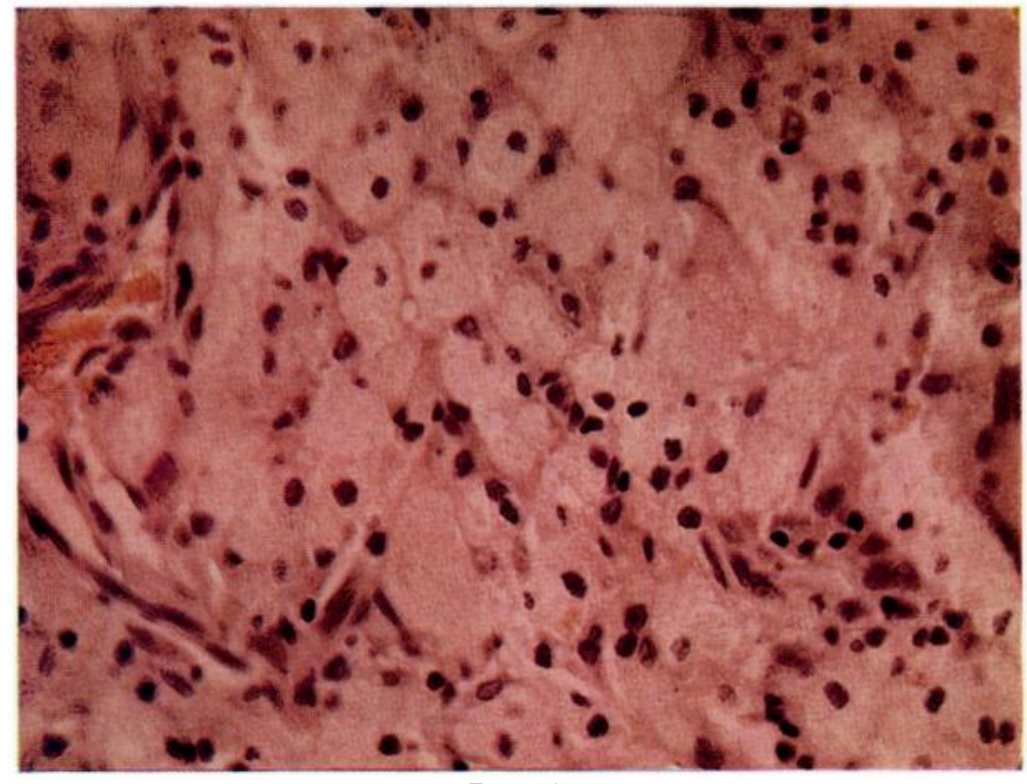

FIG. 14

High power photomicrograph of same area to show the foamy appearance of the histiocytes. (Haematoxylin and eosin, 400.)

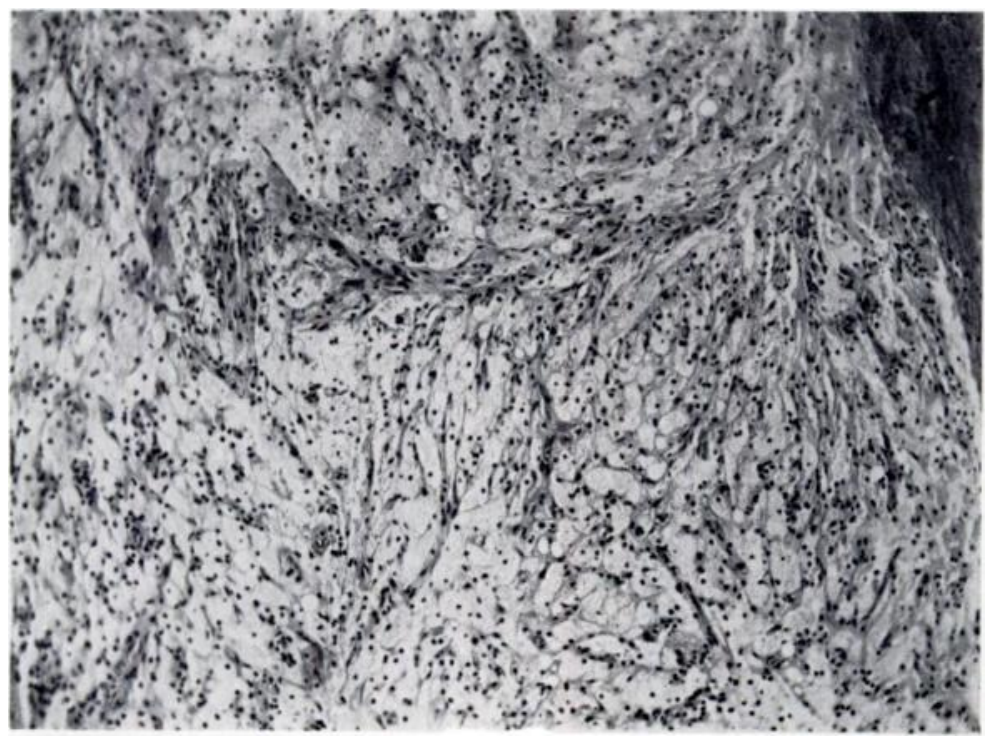

FIG. 15

Photomicrograph from the same area, but following cortisone therapy, which shows the main " histiocytic" picture to be unchanged. $(-100$.)

Biospy material from the upper end of the left femur was removed during radical saucerisation and a bone-grafting operation in November 1954.

"The specimen consists of a portion of bone, partly composed of thickened bony trabeculae showing some irregularity of the cement lines and very occasional lacunar erosion 
(Fig. 16). Some osteoblastic activity is apparent at the margins of several of the bone trabeculae. In general the marrow is abnormal showing infiltration of foamy phagocytes (Fig. 17),

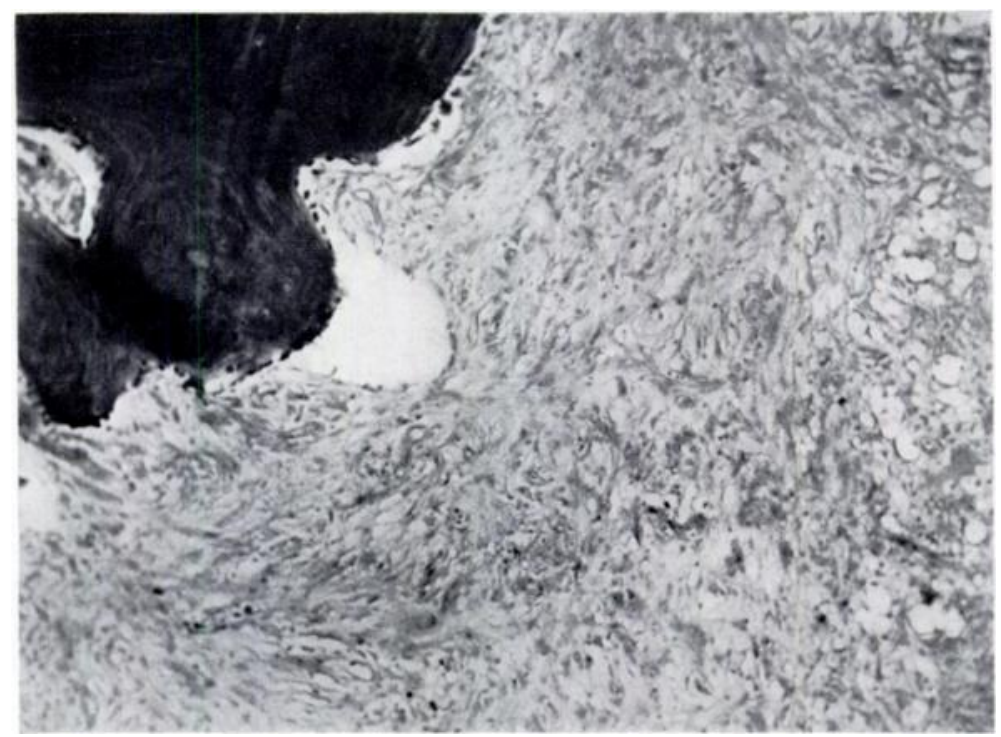

FIG. 16

Photomicrograph from the fracture area through the left femoral neck region, showing thickened bony trabeculae and some osteoblastic activity, but infiltration by "foamy" phagocytes is still marked as seen in Figure 17. $(\times 100$.

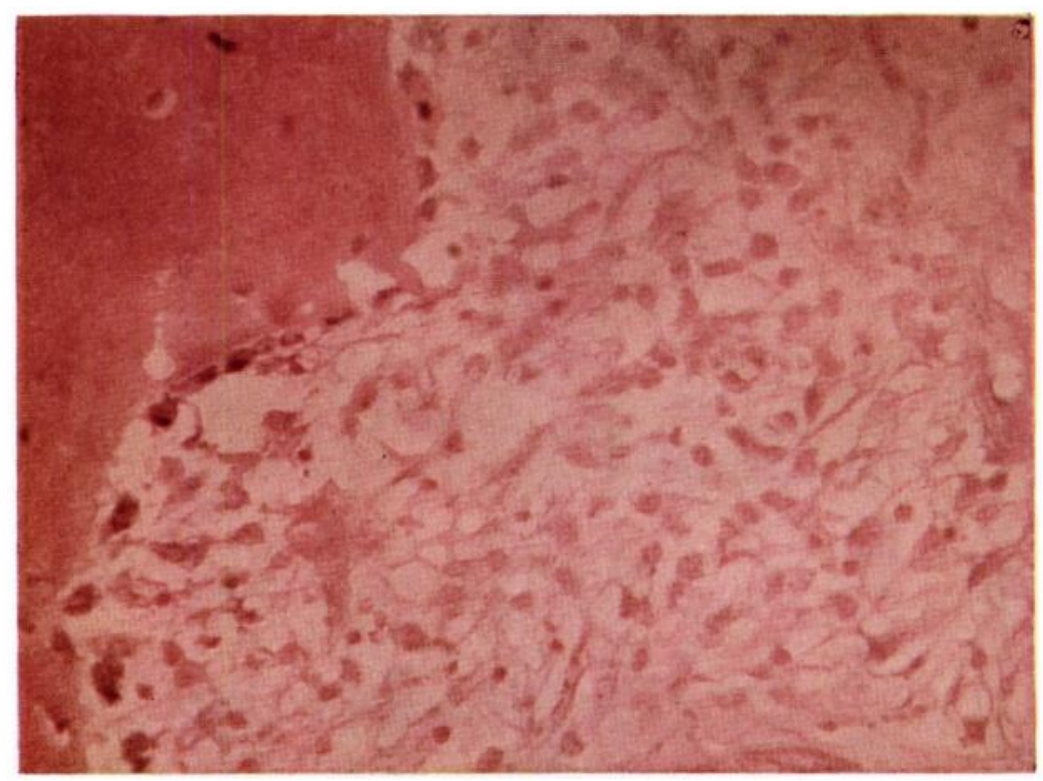

Fig. 17

Photomicrograph from the same area, to show cortical bone lined with osteoblasts and "foam cells." (Haematoxylin and eosin, $\times 400$.)

surrounding cleft-like spaces. The appearances suggest phagocytosis of lipoids, which have produced a fairly marked outgrowth of the fibrous stroma.

"This suggests continued activity of the lipoidosis of Hand-Schüller-Christian disease." 
Haematological studies-The blood picture remained normal except for a moderate hypochromic anaemia and a raised erythrocyte sedimentation rate varying between 40 millimetres/first hour and 65 millimetres/first hour-a typical "blood picture" being: polymorphonuclear leucocytes 80 per cent; lymphocytes 13 per cent; monocytes 5 per cent; eosinophils 1 per cent; reticulocytes 1 per cent.

Sternal marrow biopsy (November 1951) - "The marrow is reactive-normoblastic and leucopoietic. There are considerable numbers of typical plasma cells diffusely scattered throughout the haemopoietic islets, but no appearance which would indicate the presence of plasmocytoma in this biopsy. There is no indication of lipoidosis. There is an eosinophil myleocytic predominance compatible with a peripheral eosinophilia."

Blood chemistry-Serum calcium, inorganic phosphates, phosphorus and cholesterol were always within normal limits.

Endocrine system-There was no evidence to suggest any endocrine dysfunction, such as diabetes insipidus or hypogonadism.

\section{TREATMENT 1951-1955}

Immobilisation in a plaster-of-Paris posterior shell was carried out with fixation of the patient's right humerus in a plaster arm extension appliance. A high protein diet with supplementary vitamins was given with oral iron therapy.

Radiotherapy-Because of the lack of much response to the original course of $x$-ray therapy in 1949, Professor R. McWhirter, considered that further treatment of this nature was not to be recommended. However, in 1953 a course of nitrogen mustard was tried over a period of two months, but no obvious change in condition was noted.

Cortisone therapy-After the episode of multiple pathological fractures in 1951 and because of her poor general condition with cachexia, low grade pyrexia and a raised sedimentation rate, cortisone was given orally for three weeks. The rationale for this form of therapy was the eosinophilic character on biopsy and the observation by Donohue et al. (1950) of some temporary improvement in cases of eosinophilic leukaemia when treated with A.C.T.H. therapy. However, although the general condition of the patient improved, there was no cellular alteration in the pathology on biopsy and any improvement was most probably due to the immobilisation.

Operative treatment-In November 1954 it was decided that because there had been no evidence of bone repair in any of the lesions except in the fractured humerus, any attempt to alter the balance in favour of bone regeneration was justified. Hence radical saucerisation of the diseased area in the region of the pathological fractures in both femora was carried out and the areas were packed with cancellous bone from the bone bank. After six months' immobilisation, although there was little evidence of new bone formation, an attempt to mobilise the patient was decided upon. Following physiotherapy, bilateral non-weight-bearing walking calipers were tried, and walking with crutches finally achieved.

\section{DISCUSSION}

Etiology and pathogenesis-This condition has been defined by Jaffe and Lichtenstein as a " specific inflammatory histiocytosis, whatever its etiological agent may ultimately prove to be." It is regarded as being primarily a disease involving the reticulo-endothelial system and this accounts for its diffuse nature in both skeletal and extra-skeletal tissues, but it is still classified under the heading of "diseases of uncertain nature" as a non-lipoid histiocytosis by Payling Wright (1953). This also includes such a condition as sarcoidosis. It has been suggested as resulting from an allergic response to an unknown agent and the early clinical features of fever, raised sedimentation rate and toxaemia with the local and peripheral

VOL. $38 \mathrm{~B}$, NO. 1, fEBruARY 1956

$T_{14}$ 
eosinophilia, areas of focal necrosis, etc., may support this concept. The appearance of "foam cells" as seen in this case in the early stage could represent the usual phagocytosis by the histiocytes of degenerative debris, resulting from the necrotic process of the primary condition. It is suggested that the unknown agent could be an abnormal protein which has

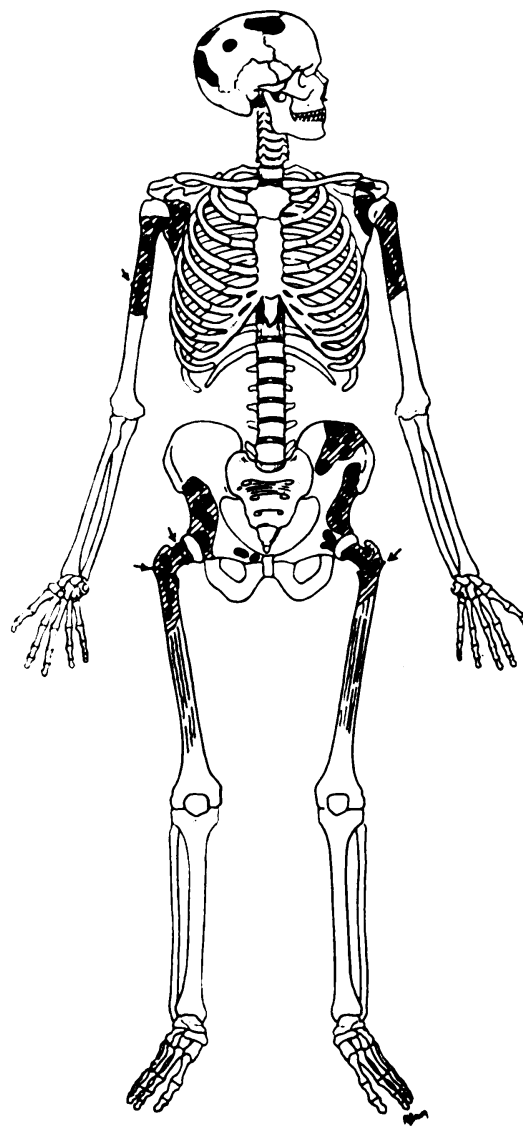

Fig. 18

Skeletal diagram to show diseased areas (in shading) with cyst-like translucent areas (in black), in the membrane bones and proximal part of the limb bones. been produced by the reticulo-endothelial cells in place of the modified plasma proteins or antibodies which are normally produced by this system. It is not truly a generalised condition in the skeletal system as it is limited to the membrane bones and the proximal aspect of the limb bones only, and this is clearly seen in this case (Fig. 18). This uncertainty of localisation could be explained by our lack of knowledge of the anatomy of the reticulo-endothelial system in bone.

In the later stage of this condition, which is termed Hand-Schüller-Christian disease or lipoid granulomatosis or chronic disseminated histiocytosis (Lichtenstein 1953), the predominant cell type is now a "foam cell" or a lipoid histiocyte with the granulomatous background. The "allergic" picture of eosinophilia, focal necrosis, etc., has now disappeared. This suggests that the disease process has changed and that it is now some metabolic disturbance of the usual synthesis and storage of certain lipoids-in particular the phospho-lipoid lecithin. Because of this, there has been a tendency to group this later stage of histiocytic granulomatosis with other true lipoid storage diseases, such as xanthoma, Gaucher disease in which the lipoid is a cerebroside, Nieman-Pick disease, Tay-Sach disease, etc. Jaffe (1938) considers that the naming or differentiation of these varied conditions should be based upon the organs affected, the chemical nature of the lipid and the presence or absence of excessive amounts of the lipid in the blood. But with these latter conditions, the metabolic disorder is the primary manifestation and is not, so far as is known, the later stage of any primary disease process, therefore the condition of histiocytosis should not be included in this group.

The distribution in this case is of interest in that there is involvement of both skeletal and extra-skeletal tissues. The latter is represented by the typical changes in the lung pattern due to a histiocytic proliferation of the normal septum cells found in the pulmonary interstitial structures, of the blood-borne macrophages and the reticulo-endothelial cells in the local connective tissue. The anatomy of the reticulo-endothelial system in the respiratory system has been recently reviewed by Payling Wright (1953). Lichtenstein emphasises how clinical episodes resulting from spontaneous pneumothorax, with honeycombing of the lungs, and pulmonary fibrosis, are the "rather common hallmark" of chronic disseminated histiocytosis of Schüller-Christian disease even in the absence of obvious skeletal defects. This radiological appearance in this case simulates the condition of "eosinophilic lung" which is an acute allergic respiratory condition seen commonly in the Far Eastern countries. During the last six years there has been no obvious change in the lung field pattern and never any episodes of spontaneous pneumothorax nor other respiratory complaints noted. There are no other areas of soft tissue involvement in the spleen, liver, lymph glands, skin or more importantly 
in the cranio-hypophysial region to produce the endocrine dysfunction of diabetes insipidus or hypogonadism, etc., which one would expect with such marked calvarial involvement. The exophthalmos recorded in this case is probably coincidental, as it was noted by the patient several years before the onset of any symptoms referable to the present condition.

The normal blood chemistry is in keeping with the described condition and is one of the factors in differentiating this lesion from a truly lipoid storage disease.

Change in cellular pattern-In this case there is presented pathological evidence from biopsies carried out chronologically of the transformation from a histiocytic granulomatous stage with predominantly eosinophils to the lipoid granulomatous stage with predominantly " foam cells," during the past six years. This is in support of Farber, and Green and Farber's concept of a conversion or change of an eosinophilic granuloma to a lipoid granulomatosis. It also indicates how the pathology at a given time refers to one particular stage of one condition (Engelbreth-Holm), or represents " closely related expressions of a single nosologic entity" (Lichtenstein).

The cellular change associated with repair or healing such a fibrosis, bone regeneration, etc., although seen in the pathological fracture of the humerus, was not seen on radiology or from the biopsies in any other diseased area. In 1954 the last biopsy showed some evidence of osteoblastic activity and the production of a fibrous stroma, but this specimen was taken from a fracture site and therefore is not necessarily indicative of a generalised tendency towards healing. Indeed the healing of the fractured humerus, which was oblique in nature and therefore presented the greatest surface and stimulus to bone regeneration, must be regarded as an exceptional change in the pattern of the disease process in this patient.

It is difficult to envisage bone regeneration through these gross areas of lipoid granulomata with its poor vascularity without the stimulus of some form of trauma. The numerous reports of complete disappearance of involved areas and the healing of pathological fractures (Versiani et al. 1944, Hill 1949, and Ponseti 1948) originate mainly from the young patient in whom the stimulus to repair and growth is marked.

Treatment-Radiotherapy was given to this patient in the early stage with temporary alleviation of pain which recurred within six months. There are many varied reports of the favourable effects of this form of treatment by Ponseti (1948), and by Childs and Kennedy (1951), etc., as well as its being of little value, or having little effect (Hamilton et al. 1946). Lichtenstein rightly points out the difficulty of evaluating such treatment for such a condition with its varied expressions of stage, severity, distribution and age of patient. He also suggests that roentgen therapy may accelerate the change from the eosinophilic stage to that of a "lipoid granuloma." This could not be evaluated in this case, except that from biopsy before, the picture was of a histiocytic granuloma with numerous eosinophils, and eighteen months later it was one of a lipoid granuloma.

The cortisone therapy did not appear to have improved the patient clinically or to have changed the cellular pattern, but it should be noted that it was not given during the acute phase, in 1949, when the eosinophilic picture predominated. Independently of this case, Blahd et al. (1951) recorded the improvement of a case of Hand-Schüller-Christian disease which had responded to cortisone.

In this case the more rational approach was in deciding to operate and to excise radically the diseased area and pack with cancellous bone chips from a bone bank. Although there has been no obvious radiological evidence of bone regeneration, movement at both hip joints is now possible without pain or muscle spasm. A pseudarthrosis appears to have been produced. This patient is now walking with crutches and bilateral walking calipers. It is suggested that in adult cases of this condition, in any area which has failed to show evidence of bone regeneration or repair, especially in a fracture site of a limb bone, radical saucerisation and bone grafting should be considered.

vol. 38 B, No. 1, February 1956

$\mathrm{Tl}_{(4)}$ 
Prognosis-This must, of necessity, be guarded in this case as well as for the condition generally, especially with the multiple involvement of skeletal and extra-skeletal systems. With the involvement of the lungs, intercurrent infection, pneumothorax, cardiac failure could occur and kill. It is commonly stated that without complications this condition does not end fatally. But because of the variation of severity, the age group involved and the pathology, a prognosis cannot be accurately stated, and indeed this is in keeping with the condition generally in which even a diagnosis of certainty cannot be given until the case has been observed over years with repeated pathological studies.

We are indebted to Dr R. F. Ogilvie, Pathologist to the Royal Infirmary of Edinburgh, for his consideration and report on the pathological material in this case.

Part of this work was carried out while one of us (R. B. D.) was holding a Research Fellowship of the Scottish Hospitals Endowment Research Trust.

\section{REFERENCES}

ABt, A. F., and Denenholz, E. J. (1936): Letterer-Siwe's Disease. Splenohepatomegaly Associated with Widespread Hyperplasia of Nonlipoid-storing Macrophages: Discussion of the So-called Reticulo-Endothelioses. American Journal of Diseases of Children, 51, 499.

Blahd, W. H., Levy, M. S., and Bassett, S. H. (1951): A Case of Hand-Schüller-Christian Syndrome Treated with Cortisone. Annals of Internal Medicine, 35, 927.

CHILDS, D. S., Jun., and KenNEDY, R. L. J. (1951): Reticulo-Endotheliosis of Children: Treatment with Roentgen Rays. Radiology, 57, 653.

Donohue, W. L., Snelling, C. E., Jackson, S. H., Keith, J. D., Chute, A. L., Laski, B., and Silverthorne, N. (1950): Pituitary Adrenocorticotropic Hormone (A.C.T.H.) Therapy in Eosinophilic Leukaemia. Journal of the American Medical Association, 143, 154.

Engelbreth-Holm, J., Teilum, G., and Christiensen, E. (1944): Eosinophil Granuloma of Bone-SchüllerChristian's Disease. Acta Medica Scandinavica, 118, 292.

Fairbank, T. (1951): An Atlas of General Affections of the Skeleton. Edinburgh and London: E. \& S. Livingstone Ltd.

FARBER, S. (1941): The Nature of "Solitary or Eosinophilic Granuloma" of Bone. American Journal of Pathology, 17, 625.

Fraser, J. (1935): Skeletal Lipoid Granulomatosis (Hand-Schüller-Christian's Disease). British Journal of Surgery, 22, 800.

Green, W. T., and Farber, S. (1942): "Eosinophilic or Solitary Granuloma" of Bone. Journal of Bone and Joint Surgery, 24, 499.

Hamilton, J. B., Barner, J. L., Kennedy, P. C., and McCort, J. J. (1946): The Osseous Manifestations of Eosinophilic Granuloma; Report of Nine Cases. Radiology, 47, 445.

HiLl, R. M. (1949): Non-Specific (Eosinophilic) Granuloma of Bone. British Journal of Surgery, 37, 69.

JAFFE, R. H. (1938): The Reticulo-Endothelial System. In Handbook of Haematology. Edited by H. Downey. Vol. 2, Section 15, 973-1,271. New York: Paul B. Hoeber Inc.

Jaffe, H. L., and Lichtenstein, L. (1944): Eosinophilic Granuloma of Bone. A Condition Affecting One, Several or Many Bones, but Apparently Limited to the Skeleton, and Representing the Mildest Clinical Expression of the Peculiar Inflammatory Histiocytosis Also Underlying Letterer-Siwe Disease and SchüllerChristian Disease. Archives of Pathology, 37, 99.

Lichtenstein, L. (1953): Histiocytosis X. Integration of Eosinophilic Granuloma of Bone, "Letterer-Siwe Disease," and "Schüller-Christian Disease" as Related Manifestations of a Single Nosologic Entity. Archives of Pathology, 56, 84.

Mallory, T. B. (1942): Pathology: Diseases of Bone. New England Journal of Medicine, 227, 955.

Otani, S., and Ehrlich, J. C. (1940): Solitary Granuloma of Bone Simulating Primary Neoplasm. American Journal of Pathology, 16, 479.

PonsetI, I. (1948): Bone Lesions in Eosinophilic Granuloma, Hand-Schüller-Christian Disease, and LettererSiwe Disease. Journal of Bone and Joint Surgery, 30-A, 811.

SnAPPer, I. (1949): Medical Clinics on Bone Diseases. A Text and Atlas. Second edition. New York: Interscience Publications Inc.

Versiani, O., Figueiró, J. M., and Junqueira, M. A. (1944): Hand-Schüller-Christian's Syndrome and " Eosinophilic or Solitary Granuloma of Bone." American Journal of the Medical Sciences, 207, 161.

WeinmanN, J. P., and Sicher, H. (1955): Bone and Bones. Second edition. London: Henry Kimpton.

Wright, G. Payling (1953): The Reticulo-Endothelial System. In Recent Advances in Pathology. Edited by G. Hadfield. Sixth edition. London: J. \& A. Churchill Ltd. 